Sharif University of Technology
Scientia Iranica
Transactions E: Industrial Engineering
http://scientiairanica.sharif.edu
IRANICA

\title{
An integrated quay crane assignment and scheduling problem with several contractors in container terminals
}

\author{
M. Safaeian, F. Etebari*, and B. Vahdani \\ Department of Industrial Engineering, Faculty of Industrial and Mechanical Engineering, Qazvin Branch, Islamic Azad University, \\ Qazvin, Iran.
}

Received 20 April 2019; received in revised form 17 May 2019; accepted 26 August 2019

KEYWORDS
Quay crane
assignment;
Quay crane
scheduling;
Container terminals;
Teaching-learning-
based optimization.

\section{Introduction and literature review}

The container terminals were established in the late 1960 s to accommodate container ships traveling between Europe and the United States. The use of containers in carrying goods has many advantages: less packaging, easier and quicker loading and unloading, lower cost, and faster transfer of goods from the ship to the road trucks or rail trains. This has increased maritime shipping and plays an important role in

\footnotetext{
*. Corresponding author.

E-mail address: featebari@gmail.com (F. Etebari)
}

international trade. Container ports and terminals that accommodate vessels and provide connections to the rest of the world play a vital role in the maritime transport network. In order to reduce costs, shippers are always looking for a more economical size of containers, building larger vessels for long journeys, and improving facilities and technology for the service ships [1].

Around the world, services provided at the terminals involve the loading and unloading of goods from/to the vessels and from/to the storage yard, and vice versa. Operations that take place before the containers reach the storage yard are seaside operations, and those activities that occur after the storage of the container in the area are called yardside operations [2]. 
Due to the high cost of establishing berths and their equipment, the main focus is placed on optimizing the activities of berths and their equipment such as Quay Cranes (QCs). The first problem of a terminal is to assign a berth location and time of service to a vessel. The second problem is to assign the QCs to the ships. The larger the number of cranes assigned to a vessel, the shorter the loading/unloading time of the vessel; however, too many cranes allocated to a vessel can lead to high interference and density of displacement in the terminal area. Therefore, the objective is to optimally allocate the cranes to the vessel. The third problem is the scheduling of the QCs, which determines a processing sequence given for each crane in order to minimize loading/unloading time of the ship. Considering that Quay Crane Assignment Problem (QCAP) and QCSP have many similarities, they have been combined over and over again, which can increase the efficiency of the seaside operations. The assignment of QCs is effective in determining the sequences of QCs; thus, the QCs can become more effective in the integration of QCSP and QCAP [3].

The main goal of this research is to consider multiple contractors for loading/unloading of container ships. This study assumes that when a vessel berths, the terminal closes an agreement with a contractor for loading or unloading the goods [4]. The fixed costs include the costs of closing contract and assigning the cranes. The variable costs incurred by the port include the costs of moving cranes between the ship bays and the processing time of each crane on board [5]. The service rate of contractors varies and the multiplicity of contractors can facilitate the creation of a competitive atmosphere in the terminal. As a result, each contractor tries to improve the quality of his equipment, services, and performance and also reduce fixed and variable costs [6]. Since assigning contractors to the vessels and allocating the cranes of each contractor to the ship bays must be done without interference, the challenge is the allocation method discussed in this paper.

In recent years, operations research methods have found a hotspot in operating management and container terminals. A large number of research studies related to the operation research methods have addressed the transfer operations planning by the seaside.

The problem of the quay scheduling was first introduced by Daganzo [7]. He proposed an Mixed Integer Programming (MIP) model aimed at reducing the costs of delayed ship loading and solving the problem by exact and approximate solution methods. Kim and Park [8] studied the scheduling problem of QCs, which are the most important equipment for the terminals. By providing a mixed-integer programming model, they considered many constraints on the operation of the QCs, used the Branch \& Bound (B\&B) method and a heuristic search algorithm called Greedy Randomize Adaptive Search Procedure (GRASP) to obtain an optimal solution to the problem, and compared the results. Imai et al. [9] examined the effectiveness of the QCSP and QCAP in the functionality of a multiuser container terminal. Goodchild and Daganzo [10] reviewed the long-term impact of double cycling on berth equipment such as cranes and the usefulness of the quay. Zhang and Kim [11] tried to minimize the number of QC cycle operations for loading/unloading containers on ship bay, which resulted in the maximum number of dual cycle operations. TavakkoliMoghaddam et al. [12] presented an MIP model for assigning and scheduling QCs known as QCASP in container terminals and provided a genetic algorithm for solving real-world problems.

Since there is a large variety of terminal locating and technical equipment, Bierwirth and Meisel [13] examined a large number of optimization models of seaside operations planning at container terminals and reviewed the related literature to support the features of modeling problems and the algorithms used. Then, they presented a new classification for berth allocation and the QCSP. They specially highlighted the integration solutions that resulted in the improved performance of terminal management.

Zhihong and $\mathrm{Na}$ [14] presented a nonlinear mathematical programming model to reduce the time of servicing the ships arriving at the terminal at horizon times, taking into account the non-crossing constraint of the QCs. Chen et al. [15] presented a mixed integer programming model that addressed the unique features in scheduling problem of allocating cranes in indented berths. Legato et al. [16] proposed an improved model for the scheduling of QCs, taking into account factors such as the performance rate of each crane, safety requirements, precedence of containers, ready time, and due date of each crane, while the cranes can move in one direction (unidirectional cranes). Chen et al. [15] focused on a particular strategy for clusterbased QCSP associated with moving the unidirectional cranes in a timeline. By using this strategy called unidirectional QCSP in the literature, the problem of scheduling the QCs is improved. To solve the problem, they also used the state-of-the-art algorithm, which provided a better structure for searching for an optimal solution. Imai et al. [9] provided a strategy for Berth Template Problem (BTP) to select ships from applicants with limited time horizons. Al-Dhaheri et al. [17] focused on the problem of scheduling the QCs to minimize the processing time for each vessel; thus, their goal was to present a way to reduce the differences between the container loads stacked over a number of bays and create a balance between ship bays in the loading and unloading operations. They also 
eliminated the limitation of the unilateral movement of the quay QCs and made it possible for the QCs to move on both sides, even when the operation of one bay had not been completed. Al-Dhaheri et al. [17] proposed a new model for the QCSP, which considered the constraints of ship stability, crane displacement time, task preemption, and unidirectional movement of cranes. Because of the possibility of unexpected breakdown of cranes and a negative impact of cranes rescheduling on the planned berth, ship owners and crane operations, Liu et al. [18] studied the rescheduling of the crane with the aim of reducing negative deviations from initial scheduling. Wu and Ma [19] focused on the problem of scheduling QCs by considering the draft and trim constraints, with the goal of minimizing loading time. Agra and Oliveira [20] presented an integrated model of berth allocation, QCs assignment, and scheduling problem, which considered a set of heterogeneous cranes with discretion for time and space variables. Efficient operation of the terminal depends on proper planning of the container movement, called "stowage planning". Azevedo et al. [21] addressed the integrated problem of the $3 \mathrm{D}$ stowage planning problem and QCs scheduling problem in container vessels. Liang et al. [22] presented a coupling model to investigate the relationship between two aspects of the quay scheduling problem: task dispatch and quantity configuration of QCs. The first issue determines the loading sequence of cranes and the second issue determines the number of cranes allocated to each vessel.

Table 1 shows a summary of previous studies. It is noteworthy to mention that, apart from the study of Al-Dhaheri and Diabat [2], none of the papers considered the balance across the ship bays. On the other hand, the problem of the contractor selection out of several contractors has not been raised yet. Generally, to fill the literature gaps and highlight the main innovations of this paper, the following list is provided:

- A novel optimization model to formulate the QCAP and QCSP is developed in which multiple contractors with different characteristics are responsible for the loading or unloading of vessels;

- A Teaching and Learning Based-Optimization (TLBO) algorithm based on the specific solution structure which provides the problem constraint handling with a possibility to solve the proposed mathematical model is applied;

- To check the validation of the proposed algorithm, an exact solver is utilized to solve the small instances;

- A real case study in Shahid Rajaee port of Iran is introduced for the first time and implementation results of integrated mathematical model in this study on this port are analyzed accordingly.

The remainder of this paper is organized as follows. Section 2 presents problem description, assumptions, notations, and mathematical formulation of the problem. Section 3 discusses the solving algorithms. Section 4 provides computational results. Section 5 includes managerial insights. Finally, Section 6 concludes the paper.

\section{Problem definition}

Here, we describe the main definitions of the proposed problem along with its assumptions. Then, all notations are given and eventually, a novel optimization model is proposed.

\subsection{Problem description and assumptions}

It is a common practice in the seaside operations to partition each ship into a number of bays in which there are a number of containers. The bays are indexed in ascending order from left to right. At any moment, each crane can only be assigned to one bay for the loading/unloading of containers, which means that each crane can load/unload a container at any moment. Since all cranes move on one rail, it is important to keep in mind that the cranes do not physically collide with each other. To prevent collisions, the cranes are indexed in ascending order from left to right. Cranes with a smaller index should not be placed on the right side of the cranes with a higher index. This can be seen in Figure 1. For example, if $Q C_{1}$ of the first contractor is assigned to the second bay of the first ship, $Q C_{2}$ of the first contractor cannot be assigned to the first bay of the first ship, as it leads to interference in the cranes.

Many studies have considered the processing on just one vessel; however, in this study, a multi-vessel situation is considered, which is more compatible with the real-world situations.

Most papers have considered the non-preemption constraint, which means that no crane can be moved until processing has been completed on a ship's bay. In other words, the crane can move only when its work on the current bay is over. Since this limitation does not exist in the real world, it is not addressed in this study and, therefore, there are better answers to the problem.

Another limitation of much of the existing research is the unidirectional movement of the QCs, which forces all cranes to move in one direction and not backwards. In this paper, this limitation has been resolved and the crane has the advantage of moving even before the completion of the activities of a bay and, if necessary, can be returned to that bay. Therefore, in this study, cranes can move freely to the 


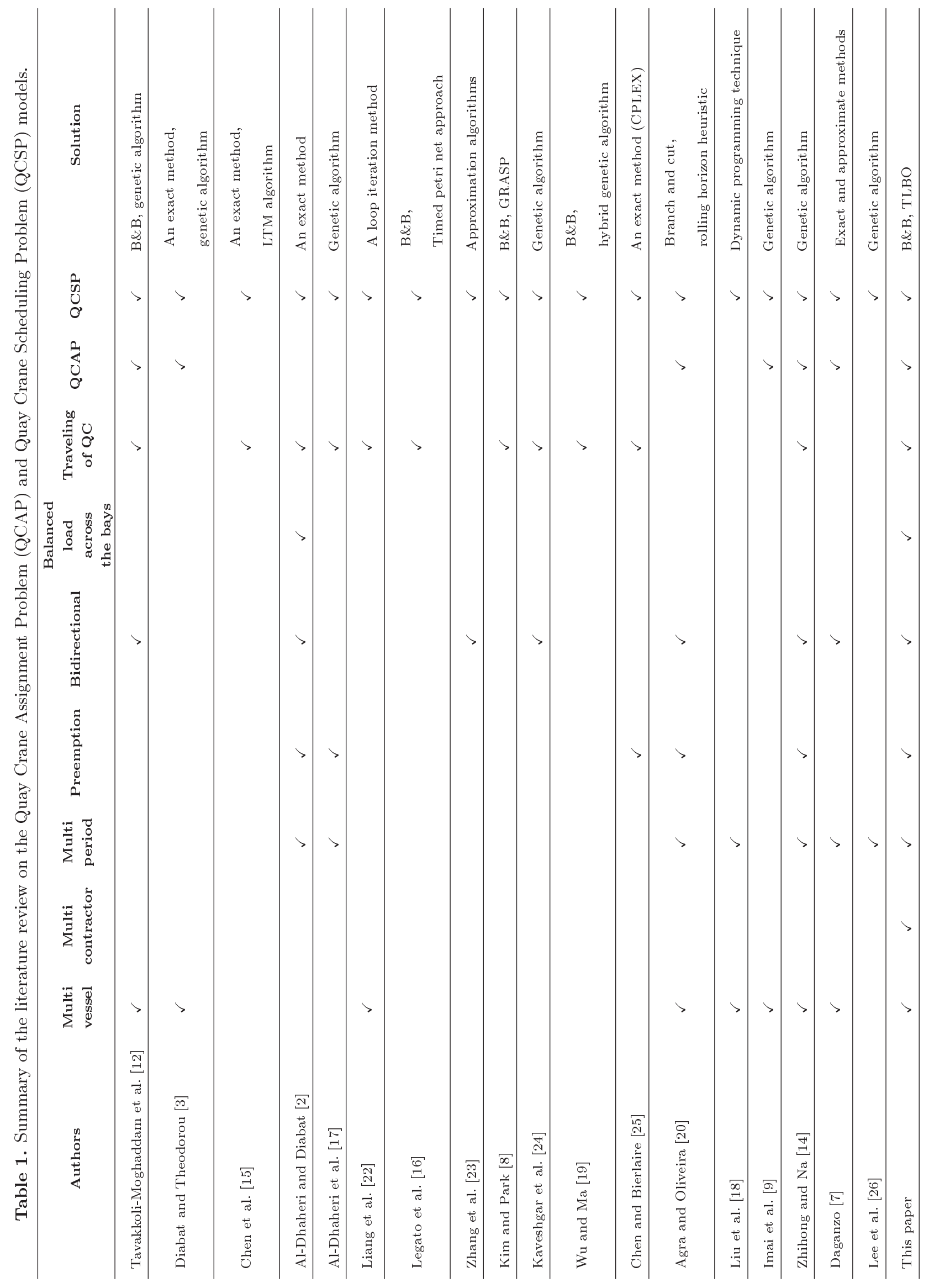




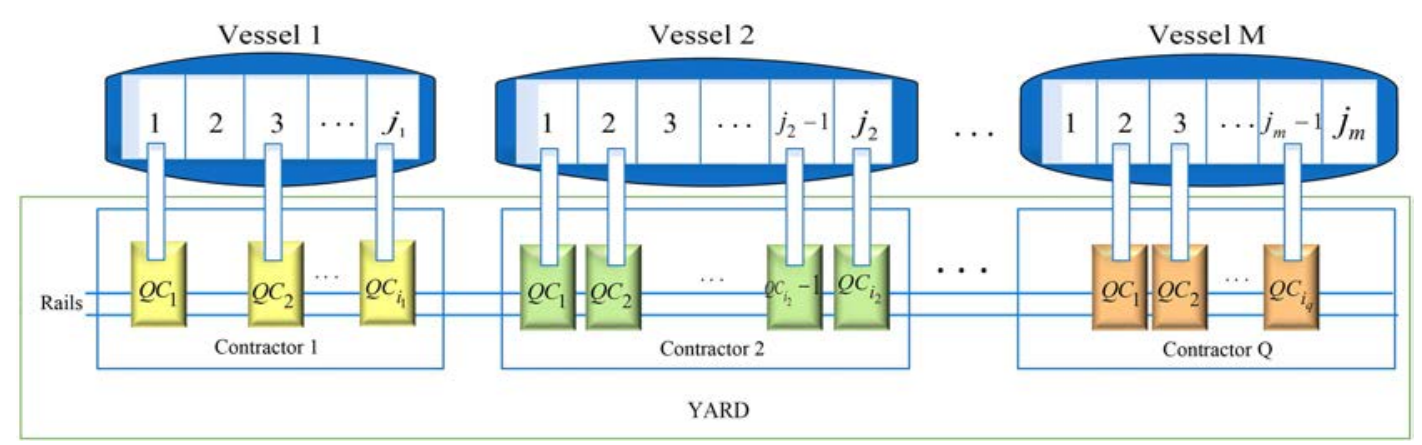

Figure 1. Graphical illustration of the Quay Crane Scheduling Problem (QCSP) with several contractors and vessels.

left and right (bidirectional move) so that they do not collide with each other.

Considering the safe margin between cranes in the real world, they can be easily added to the model. When the vessels are partitioned into a number of bays, a safe distance between the two bays can be considered virtually; therefore, a safe margin has not been considered in this study.

The existence of different contractors, each with a number of QCs, has many advantages for the terminal. The competitive environment among contractors prompts them to increase the number of cranes and the quality of their services and equipment and reduce their prices. In this research, it is assumed that each contractor has a different number of cranes and the performance rate of each contractor varies. Also, in this model, it is assumed that when a vessel docks, the berth closes a contract with a contractor for loading/unloading the vessel that incurs the fixed costs of closing the contract and allocating the crane. Then, for each time unit, the crane is used for processing (loading or unloading) and the port incurs variable costs. Since the objective function minimizes the total incurred costs in the proposed model, the cost of moving the cranes between the ship bays prevents the cranes from being displaced between bays as much as possible. As a result, a shorter time is spent on displacing the cranes across the bays. Thus, in this study, the time spent on displacing the cranes across the ship bays is ignored, while the moving cost is considered.

Given that the allocation of QCs to ship bays should not interfere with their assignment, assignment of the contractor to the ship must be done in such a way that the contractors do not interfere in each other's tasks. The exact same method used to prevent crane interference is used to prevent contractor interference in this study, too. In other words, all contractors are indexed in ascending order from left to right according to their position in the berth, and contractors with a smaller index should not be placed on the right side of contractors with a higher index. For example, as shown in Figure 1, if the second contractor is assigned to the first vessel, the first contractor cannot be assigned to the second vessel. Moreover, a soft time window is set to determine the time allowed for loading/unloading the ships, and the profit from the earliness penalties due to tardiness in completing the ship's processing is included in the model.

The main assumptions in these explicit forms are as follows:

- Each vessel is partitioned into several bays;

- Each vessel is assigned to a maximum of one contractor for servicing;

- Each ship bay is allocated to a maximum of one crane for loading/unloading;

- The crane activity can be loading or unloading;

- Consider multiple contractors for assigning to vessels;

- Each contractor runs and operates several QCs;

- The performance rate of each contractor's crane differs from another;

- Soft time window is considered to serve each ship;

- Preemption is allowed;

- Cranes can move freely to the left and right (Bidirectional is allowed);

- Several time periods are considered;

- The cost of moving cranes between the ship bays is considered;

- Creating balance in the number of the remaining containers on each ship bay has been considered.

\subsection{Notations}

Table 2 defines the sets, parameters, and decision variables used in the formulation of the problem. 
Table 2. Sets, parameters, and decision variables.

\begin{tabular}{|c|c|}
\hline \multicolumn{2}{|l|}{ Sets: } \\
\hline$M$ & Number of vessels $(m=1,2, \cdots, M)$ \\
\hline$Q$ & Number of contactors $(q=1,2, \cdots, Q)$ \\
\hline$T$ & Number of planning periods $(t=1,2, \cdots, T)$ \\
\hline$J_{m}$ & Number of bays of vessels $m\left(j=1,2, \cdots, J_{m}\right)$ \\
\hline$I_{q}$ & Number of quay cranes of contractor $q$ \\
\hline \multicolumn{2}{|c|}{ Parameters: } \\
\hline$\mu_{q}$ & The identical rate of operation for contractor $q$ \\
\hline$\omega_{j m}$ & Workload in containers at bay $j$ of vessel $m$ to be handled \\
\hline$D_{m}$ & Due date of vessel $m$ \\
\hline$R_{m}$ & Tardiness cost of vessel $m$ \\
\hline$R_{m}^{\prime}$ & Earliness income of vessel $m$ \\
\hline$C$ & The cost of difference between the workload remaining for every bays of vessels \\
\hline$C^{\prime}$ & Fixed cost of using (allocating) the QC \\
\hline$C_{q m}^{\prime \prime}$ & Fixed cost of using (allocating) the $q$ th contractor to the $m$ th vessel \\
\hline$\lambda_{i j j^{\prime} q m}$ & Travel cost of the $i$ th QC of the contractor $Q$ th from the $j$ th bay to the $j^{\prime}$ th bay from vessel $m$ \\
\hline$I_{m}$ & Variable cost of using QC on vessel $m$ \\
\hline$M$ & Big $M$, sufficiently large number \\
\hline \multirow{2}{*}{\multicolumn{2}{|c|}{$\begin{array}{l}\text { Decision } \\
\text { variables: }\end{array}$}} \\
\hline & \\
\hline$x_{i j q m}^{t}$ & $\begin{array}{l}\text { A binary decision variable which is } 1 \text { if the } i \text { th } \mathrm{QC} \text { of the } q \text { th contractor is assigned to } j \text { th bay of } \\
\text { vessel } m \text { at time } t \text {, and } 0 \text { otherwise }\end{array}$ \\
\hline$w_{j m}^{t}$ & The unhandled workload at time $t$ in the $j$ th bay of the $m$ th vessel \\
\hline$w_{t j j^{\prime} m}^{\prime t}$ & The difference between the workload existing in bay $j$ and bay $j^{\prime}$ of vessel $m$ at time $t$ \\
\hline$Z_{q m}$ & A binary decision variable which is 1 if the $Q$ th contractor is assigned to $m$ th vessel, and 0 otherwise \\
\hline$y_{i j j^{\prime} q m}^{t}$ & $\begin{array}{l}\text { A binary decision variable which is } 1 \text { if the } i \text { th } \mathrm{QC} \text { of } q \text { th contractor is moved from bay } j \text { to bay } j^{\prime} \text { of } \\
\text { vessel } m \text { at time } t \text {, and } 0 \text { otherwise }\end{array}$ \\
\hline$T_{m t}^{j}$ & A binary decision variable which is 1 if bay $j$ of vessel $m$ is handled at time $t$, and 0 otherwise \\
\hline$v_{j m}^{t}$ & Level of inventory at time $t$ in the $j$ th bay of the $m$ th vessel \\
\hline$\alpha_{j m}^{t}$ & $\begin{array}{l}\text { A binary decision variable which is } 1 \text { if level of inventory in } j \text { th bay of } m \text { th vessel at time } t \text { is positive, } \\
\text { and } 0 \text { otherwise }\end{array}$ \\
\hline$T_{m}^{\prime}$ & Completion time of vessel $m$ \\
\hline$F_{m}$ & Tardiness of vessel $m$ \\
\hline$E_{m}$ & Earliness of vessel $m$ \\
\hline
\end{tabular}

\subsection{Mathematical modelling}

$$
\begin{aligned}
\min \sum_{m}^{M} \sum_{j}^{J_{m}} \sum_{j^{\prime}}^{J_{m}} \sum_{t}^{T} C \cdot\left|w_{j m}^{t}-w_{j^{\prime} m}^{t}\right| \\
+\sum_{m}^{M} \sum_{q}^{Q} \sum_{i}^{I_{q}} \sum_{j}^{J_{m}} \sum_{t}^{T} C^{\prime} x_{i j q m}^{t} \\
+\sum_{q}^{Q} \sum_{m}^{M} C_{q m}^{\prime \prime} Z_{q m} \\
+\sum_{m} \sum_{q}^{Q} \sum_{i}^{I_{q}} \sum_{j}^{J_{m}} \sum_{j^{\prime}}^{J_{m}} \sum_{t}^{T} \lambda_{i j j^{\prime} q m} y_{i j j^{\prime} q m}^{t} \\
+\sum_{m} F_{m} R_{m}-\sum_{m} E_{m} R_{m}^{\prime}+\sum_{m} I_{m} T_{m}^{\prime} .
\end{aligned}
$$

s.t.:

$$
\begin{aligned}
& \sum_{m=1}^{M} \sum_{j=1}^{J_{m}} x_{i j q m}^{t} \leq 1 \\
& \forall q=1, \ldots, Q, \quad \forall i=1, \ldots, I_{q}, \quad \forall t=1, \ldots, T, \\
& \sum_{q=1}^{Q} \sum_{i=1}^{I_{q}} x_{i j q m}^{t} \leq 1 \\
& \forall j=1, \cdots, J_{m}, \quad \forall t=1, \cdots, T, \\
& \quad \forall m=1, \cdots, M, \\
& \sum_{t=1}^{T} \sum_{q=1}^{Q} \sum_{i=1}^{I_{q}} \mu_{q} x_{i j q m}^{t} \geq \omega_{j m} \\
& \quad \forall j=1, \cdots, J_{m}, \quad \forall m=1, \cdots, M,
\end{aligned}
$$




$$
\begin{aligned}
& v_{j m}^{1}=\omega_{j m}-\sum_{i=1}^{I_{q}} \sum_{q=1}^{Q} \mu_{q} \cdot x_{i j q m}^{1} \\
& \sum_{j=1}^{J_{m}} \sum_{i=1}^{I_{q}} \sum_{t=1}^{T} x_{i j q m}^{t} \leq Z_{q m} \cdot M \\
& \forall j=1, \cdots, J_{m}, \quad \forall m=1, \cdots, M, \\
& \forall q=1, \cdots, Q, \quad \forall m=1, \cdots, M, \\
& v_{j m}^{t}=v_{j m}^{t-1}-\sum_{i=1}^{I_{q}} \sum_{q=1}^{Q} \mu_{q} \cdot x_{i j q m}^{t} \\
& \sum_{m=1}^{M} Z_{q m} \leq 1 \quad \forall q=1, \cdots, Q, \\
& \forall j=1, \cdots, J_{m}, \quad \forall m=1, \cdots, M, \\
& \forall t=2, \cdots, T \text {, } \\
& v_{j m}^{t} \leq M \cdot \alpha_{j m}^{t} \\
& \forall j=1, \cdots, J_{m}, \quad \forall m=1, \cdots, M, \\
& \forall t=1, \cdots, T \text {, } \\
& v_{j m}^{t} \geq-M .\left(1-\alpha_{j m}^{t}\right) \\
& \forall j=1, \cdots, J_{m}, \quad \forall m=1, \cdots, M, \\
& \forall t=1, \cdots, T \text {, } \\
& w_{j m}^{t} \leq v_{j m}^{t}+M \cdot\left(1-\alpha_{j m}^{t}\right) \\
& \forall j=1, \cdots, J_{m}, \quad \forall m=1, \cdots, M, \\
& \forall t=1, \cdots, T \text {, } \\
& w_{j m}^{t} \geq v_{j m}^{t}-M \cdot\left(1-\alpha_{j m}^{t}\right) \\
& \forall j=1, \cdots, J_{m}, \quad \forall m=1, \cdots, M, \\
& \forall t=1, \cdots, T \text {, } \\
& w_{j m}^{t} \leq \alpha_{j m}^{t} \cdot M \\
& \forall j=1, \cdots, J_{m}, \quad \forall m=1, \cdots, M, \\
& \forall t=1, \cdots, T \text {, } \\
& \sum_{i^{\prime}=i+1}^{I_{q}} \sum_{j^{\prime}=1}^{J_{m-1}} x_{i^{\prime} j^{\prime} q m}^{t} \leq M\left(1-x_{i j q m}^{t}\right) \\
& \forall q=1, \cdots, Q, \quad \forall i=1, \cdots, I_{q}, \\
& \forall j=1, \cdots, J_{m}, \quad \forall t=1, \cdots, T, \\
& \forall m=1, \cdots, M, \\
& \sum_{q^{\prime}=q+1}^{Q} \sum_{m^{\prime}=1}^{m-1} Z_{q^{\prime} m^{\prime}} \leq M\left(1-Z_{q m}\right) \\
& \forall m=1, \cdots, M, \quad \forall q=1, \cdots, Q-1, \\
& \sum_{q=1}^{Q} Z_{q m}=1 \quad \forall m=1, \cdots, M, \\
& \sum_{q=1}^{Q} \sum_{i=1}^{I_{q}} x_{i j q m}^{1}=T_{j m 1} \\
& \forall j=1, \cdots, J_{m}, \quad \forall m=1, \cdots, M, \\
& \sum_{q=1}^{Q} \sum_{i=1}^{I_{q}} x_{i j q m}^{t}-M \cdot \sum_{\tau=1}^{T-1} T_{j m \tau} \leq T_{j m t} \\
& \forall j=1, \cdots, J_{m}, \quad \forall m=1, \cdots, M, \\
& \forall t=1, \cdots, T, \\
& T_{m}^{\prime} \geq T_{j m t} . t \\
& \forall m=1, \cdots, M, \quad \forall j=1, \cdots, J_{m}, \\
& \forall t=1, \cdots, T \text {, } \\
& E_{m}-F_{m}=D_{m}-T_{m}^{\prime} \quad \forall m=1, \cdots, M, \\
& y_{i j j^{\prime} q m}^{t} \geq x_{i j q m}^{t}+x_{i j^{\prime} q m}^{t+1}-1 \\
& \forall i=1, \cdots, I_{q}, \quad \forall j=1, \cdots, J_{m}, \\
& \forall j^{\prime}=1, \cdots, J_{m}, \quad j \neq j^{\prime}, \quad \forall q=1, \cdots, Q, \\
& \forall m=1, \cdots, M, \quad \forall t=1, \cdots, T-1, \\
& x_{i j q m}^{t} \in\{0,1\} \quad \forall i=1, \cdots, I_{q}, \\
& \forall j=1, \cdots, J_{m}, \quad \forall q=1, \cdots, Q, \\
& \forall m=1, \cdots, M, \quad \forall t=1, \cdots, T, \\
& w_{j m}^{t} \geq 0 \quad \forall j=1, \cdots, J_{m}, \\
& \forall m=1, \cdots, M, \quad \forall t=1, \cdots, T, \\
& E_{m}, F_{m}, T_{m}^{\prime} \geq 0 \quad \forall m=1, \cdots, M, \\
& Z_{q m} \in\{0,1\} \\
& \forall q=1, \cdots, Q, \quad \forall m=1, \cdots, M, \\
& y_{i j j^{\prime} q m}^{t} \in\{0,1\} \quad \forall i=1, \cdots, I_{q},
\end{aligned}
$$




$$
\begin{array}{cc}
\forall j=1, \cdots, J_{m}, & \forall j^{\prime}=1, \cdots, J_{m}, \\
\forall q=1, \cdots, Q, & \forall m=1, \cdots, M, \\
T_{m j t} \in\{0,1\} & \forall m=1, \cdots, M, \\
\forall j=1, \cdots, J_{m}, & \forall t=1, \cdots, T, \\
\alpha_{j m}^{t} \in\{0,1\} & \forall m=1, \cdots, M, \\
\forall j=1, \cdots, J_{m}, & \forall t=1, \cdots, T, \\
v_{j m}^{t} \in \text { free } & \forall m=1, \cdots, M, \\
\forall j=1, \cdots, J_{m}, & \forall t=1, \cdots, T .
\end{array}
$$

In this model, the objective function (1) in all vessels minimizes the sum of difference in the remaining workload on both bays of the ship; in addition, it prevents the allocation of cranes to ship bays in the subsequent time periods. It also minimizes the costs of assigning the contractor, displacing the cranes between bays, and deviating from due date and processing (loading or unloading) on each vessel while also maximizing the profit from earliness. Since the objective function is nonlinear, it is converted to a linear relation with the aid of Eqs. (30)-(33), which will be explained in more detail. Constraint (2) shows that the crane of each contractor is assigned at any time to a maximum of one ship bay. Constraint (3) shows that each ship bay can be serviced by at most one crane of one contractor at any given time. Constraint (4) ensures that the number of cranes assigned to each bay is sufficient to complete the operation on that bay. With the help of Constraints (5) and (6), the inventory level of ships bays is calculated for all time periods. By using Constraints (7) and (8), if the inventory level is positive $\left(v_{j m}^{t}>0\right)$, Constraint (8) is deactivated and $\alpha_{j m}^{t}$ is equal to 1 , and if $v_{j m}^{t}<0$, Constraint (7) is deactivated and $\alpha_{j m}^{t}$ is equal to 0 . Constraints (9), (10), and (11) determine the relationships between variables $\alpha_{j m}^{t}, v_{j m}^{t}$, and $w_{j m}^{t}$. If $\alpha_{j m}^{t}=1$, the variables $v_{j m}^{t}, w_{j m}^{t}$ are the same and if $\alpha_{j m}^{t}=0$, then $w_{j m}^{t}=$ 0 . Constraint (12) prevents the interference in the allocation of cranes to ships' bays. The indexing of ship bays and cranes is arranged in ascending order based on their position so that it is not allowed to place a high index crane on the left side of the lower index crane. Constraint (13) prevents interference of contractors with their ship assignments. Similar to Constraint (12), the indexing of contractors and ships is arranged in ascending order according to their position. Constraint (14) indicates that if the contractor $q$ is not assigned to the vessel $m$, there is no possibility of assigning cranes of contractor $q$ to the vessel $m$, and if the contractor $q$ is assigned to the vessel $m$, the cranes of the contractor $q$ can be assigned to the vessel $m$.
Constraint (15) indicates that each contractor can be assigned to at most one vessel, and Constraint (16) ensures that each vessel is assigned exactly to one contractor for servicing. Constraints (17) and (18) measure the completion time of each bay. Because the service to any vessel ends when the loading/unloading of all bays of that vessel is completed, Constraint (19) calculates the completion time of each ship. By obtaining the completion time of the vessel and calculating the time difference with the due date, Constraint (20) determines the tardiness or earliness of each ship. Constraint (21) determines the movements carried out by each crane of a contractor. Constraints (22) to (29) are employed to determine the range of decision variables.

In order to linearize the objective function, the objective function (1) is rewritten into Eq. (30) and Constraints (31)-(33) are added to it.

$$
\begin{aligned}
& \min \sum_{m}^{M} \sum_{j}^{J_{m}} \sum_{j^{\prime}}^{J_{m}} \sum_{t}^{T} C . w_{j j^{\prime} m}^{\prime t} \\
& +\sum_{m}^{M} \sum_{q}^{Q} \sum_{i}^{I_{q}} \sum_{j}^{J_{m}} \sum_{t}^{T} C^{\prime} t x_{i j q m}^{t} \\
& +\sum_{q}^{Q} \sum_{m}^{M} C_{q m}^{\prime \prime} Z_{q m} \\
& +\sum_{m}^{M} \sum_{q}^{Q} \sum_{i}^{I_{q}} \sum_{j}^{J_{m}} \sum_{j^{\prime}}^{J_{m}} \sum_{t}^{T} \lambda_{i j j^{\prime} q m} y_{i j j^{\prime} q m}^{t} \\
& +\sum_{m}^{M} F_{m} R_{m}+\sum_{m}^{M} E_{m} R_{m}^{\prime}+\sum_{m}^{M} I_{m} T_{m}^{\prime}, \\
& w_{j j^{\prime} m}^{t} \geq w_{j m}^{t}-w_{j^{\prime} m}^{t} \\
& \forall j=1, \cdots, J_{m}, \quad \forall j^{\prime}=1, \cdots, J_{m}, \\
& \forall m=1, \cdots, M, \quad \forall t=1, \cdots, T, \\
& w_{j j^{\prime} m}^{t} \geq w_{j^{\prime} m}^{t}-w_{j m}^{t} \\
& \forall j=1, \cdots, J_{m}, \quad \forall j^{\prime}=1, \cdots, J_{m}, \\
& \forall m=1, \cdots, M, \quad \forall t=1, \cdots, T, \\
& w_{j j^{\prime} m}^{\prime t} \geq 0 \\
& \forall j=1, \cdots, J_{m}, \quad \forall j^{\prime}=1, \cdots, J_{m}, \\
& \forall m=1, \cdots, M, \quad \forall t=1, \cdots, T .
\end{aligned}
$$


In the above formulation, the same as Eq. (1), the first term in the objective function has been used to minimize workload difference and create a balance across all bays in all vessels; the second term prevents the allocation of the cranes to the ship bays in the subsequent time periods, and the third to seventh terms minimize other costs and maximize profit. This formulation method used for describing the problem makes the programming model linear and Constraints (31) and (32) are added to the problem. Constraint (33) determines the range of the decision variables.

\section{Solution procedure}

The last decade has seen a rapid development of metaheuristics along with their applications in different engineering trends [27]. As already applied to solve similar complicated optimization problems, the OTLBO Algorithm has never been applied in this research area. This reason motivates us to propose the TLBO inspired by the teaching and learning process to solve the proposed integrated optimization model. It is one of the newest intelligent optimization algorithms $[28,29]$. This algorithm has the smallest possible number of parameters, and in this regard, it has a special privilege. We first explain the teaching and learning algorithm and then, introduce the structure of each solution or each student in the algorithm.

To explain the algorithm, assume that two different teachers, $T_{1}$ and $T_{2}$, teach the same subject with the same content in two different classes with an equal learning level. It is assumed that the grades obtained by the students follow the normal distribution so that $\sigma^{2}$ represents the variance, $\mu$ denotes the mean, and $x$ refers to the value for the normal distribution function. The normal distribution is defined as Eq. (34):

$$
f(X)=\frac{1}{\delta \sqrt{2 \pi}} e^{\frac{-(x-\mu)^{2}}{2 \delta^{2}}} .
$$

In Figure 2, Curves 1 and 2 illustrate students' marks in two classes taught and evaluated by $T_{1}$ and $T_{2}$. Since a good teacher yields a better average for the results of his/her students and in this figure, the average curve 2 differs greatly from the mean curve 1 , the second teacher's students have better marks than the first teacher's. Thus, $T_{2}$ outperformed $T_{1}$ in his/her teaching period.

In the above process of learning, a mathematical model is prepared and implemented to optimize a nonlinear and nonconvex function, thus developing a new technique called TLBO. Suppose that in curve $A, M_{A}$ is the average marks obtained by the students of a class and the most intelligent person in the population is selected as a teacher. Therefore, in the best condition, the performance of the best student is similar to that of the teacher, as shown in Figure 3

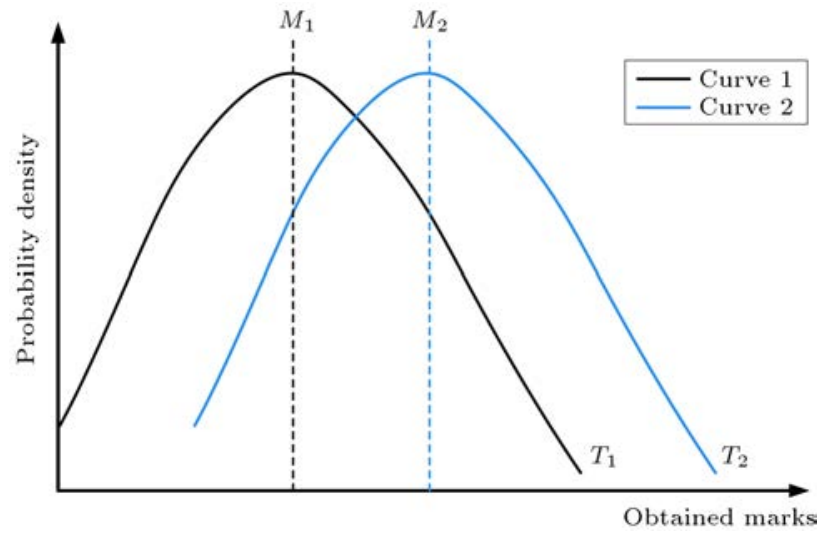

Figure 2. Distribution of marks obtained by learners taught by two different teachers [30].

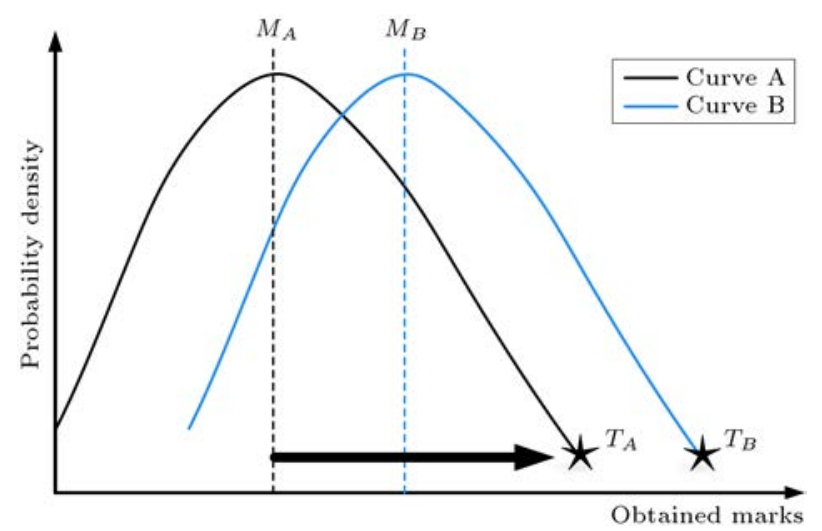

Figure 3. Model for the distribution of marks obtained for a group of learners [30].

by $T_{A}$. As the average grade of the class increases with increasing teacher abilities, the teacher tries to spread his knowledge among students in order to raise their mean marks. As the learning level increases, $M_{A}$ transcends $M_{B}$. $T_{A}$ attempts to increase the mean scores of the students from $M_{A}$ to $M_{B}$; in the next step, the students need a new teacher superior to them. In this example, $T_{B}$ has the best performance in curve $B$ and can be considered as a new teacher.

Like all other nature-inspired algorithms, the TLBO is a population-based algorithm. The TLBO population is a group of students or a classroom. Because the population consists of various variables for problem solving in optimization algorithms, different designed variables of the TLBO are compared through various responses proposed by the students, and the result of the interaction between each student and a good student is compared with that of another solution based on optimization techniques, resulting in the best solution as a teacher.

The TLBO process is divided into two parts: teacher's phase and student's phase, to be elaborated below. Figure 4 shows the general pseudo-code of the teaching and learning algorithm. 


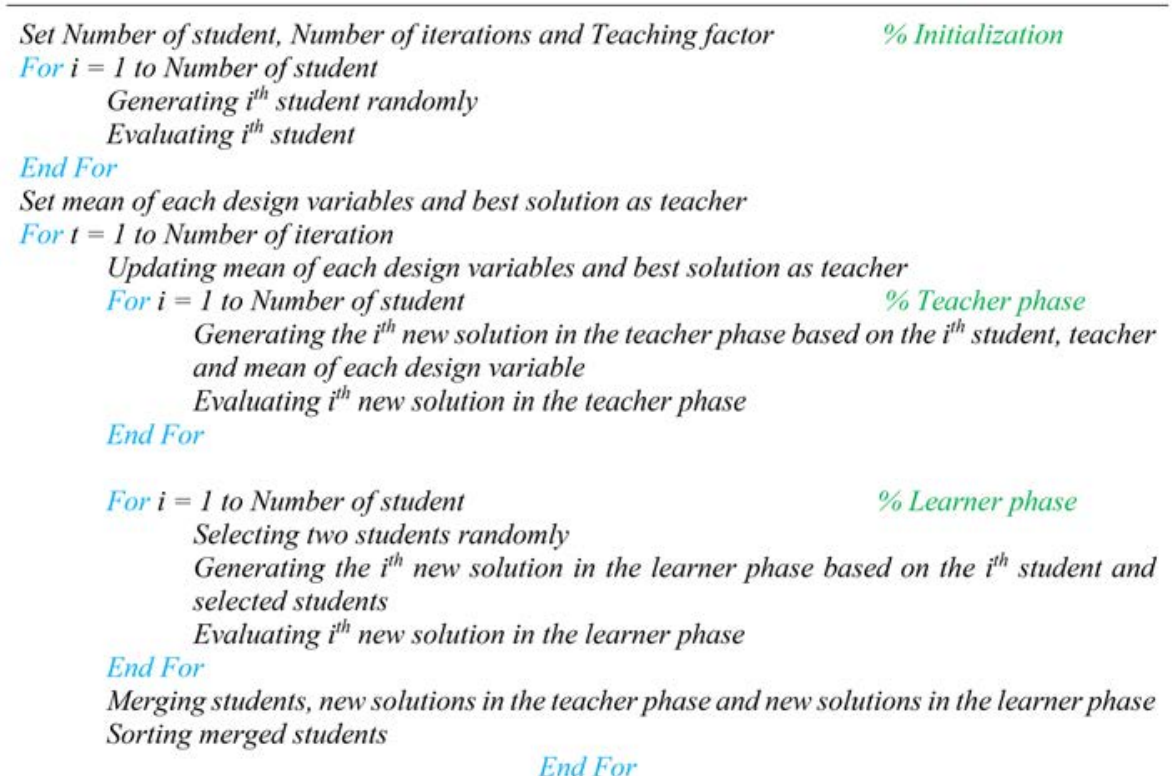

Figure 4. The pseudo-code of the Teachin-Learning-Based-Optimization (TLBO) algorithm.

The higher average mark depends on a good teacher. A good teacher is the one who makes his students reach his professional level during studying. However, in reality, this is not possible and a teacher can only move the average knowledge of the class students according to the ability of the class. This is a random process that depends on a number of factors.

If $M_{i}$ denotes mean and $T_{i}$ teacher in iteration $i$, the teacher will attempt to move the mean such that it reaches his level; therefore, we will name the new mean $T_{i}$ as $M_{\text {New }}$. The update process is done according to the difference between the new and existing means as follows:

Difference $\operatorname{mean}_{i}=r_{i}\left(T_{i}-T_{F} M_{i}\right)$.

These changes update the existing solution as follows:

$$
X_{\text {new }, i}=X_{\text {old }, i}+\text { Difference } \operatorname{mean}_{i} .
$$

Increasing learners' knowledge can be reviewed from two different angles, one through the teacher and the other through interactions between students. A learner interacts randomly with other learners through group discussions, communication, etc. A student can learn new things from another classmate if this student has more knowledge than the first student.

Learners can widen the scope of their knowledge through the teacher and through interactions between themselves such as group discussion, communication, etc. If a student has a higher level of knowledge, other students can learn from him.

\subsection{Solution structure representation}

As a metaheuristic, it is essential to define an encoding plan to implement the solution of the proposed
TLBO [31-35]. The structure of the solution presented in this paper consists of three rectangular matrices (Figure 5). Each contractor with his cranes is shown with the same color and bays of each vessel are shown with the same hachure.

The first matrix, called matrix $P$, is a random permutation of numbers one to $q_{\max }$ in $1 \times q_{\max }$ dimension and it determines the contractor assigned to each vessel, which is determined at the beginning of the time horizon. Since each vessel must be assigned exactly to one contractor, $m_{\text {max }}$, the first separated gene is arranged in ascending order from left to right and assigned to the vessels. $q_{\max }$ and $m_{\max }$ represent the number of contractors and vessels, respectively. It should be noted that contractors assigned to vessels will be fixed until completion of loading/unloading operations of vessels. The second matrix, called the matrix $K$, consists of random binary numbers in $t \times$ $\sum_{m} j_{m}$ dimensions and $j_{m}$ represents the number of bays per vessel. Genes with a value of 1 represent the bays that are being serviced by the crane in the period related to them. The third matrix, the so-called matrix $j$, is a random permutation of numbers from 1 to $\sum_{q} I_{q}$ with $t \times \sum_{q} I_{q}$ dimensions and $I_{q}$ represents the number of cranes for each contractor. This matrix determines the cranes assigned to each bay of the vessel where in each time period, the contractors' cranes that have been selected are separated and assigned to bays whose cranes must be assigned to them in accordance with the matrix $K$. Then, in order to avoid the interference among the assigned cranes, the indexes of cranes are arranged in ascending order and allocated to the ship bays.

The designed solution structure satisfies all the 

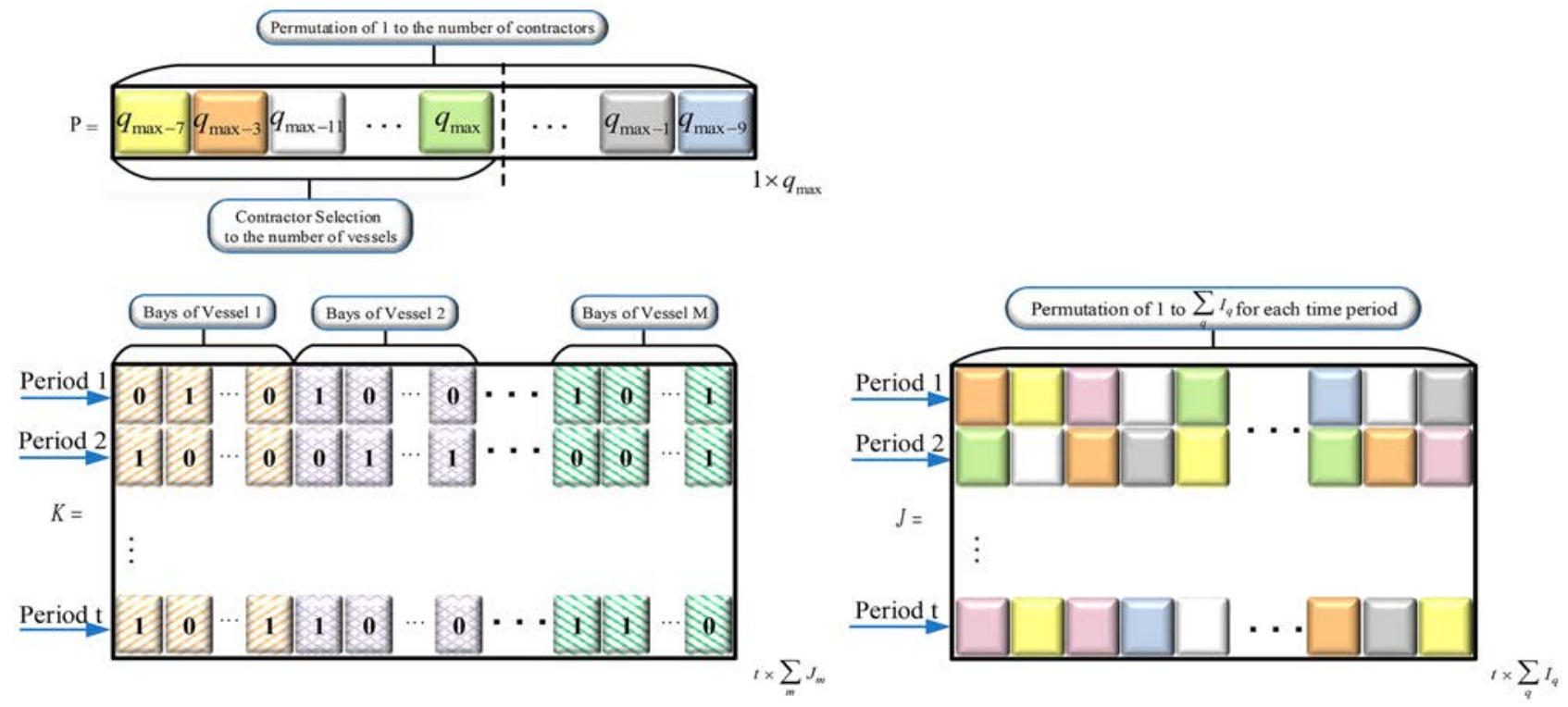

Figure 5. Student structure representation.
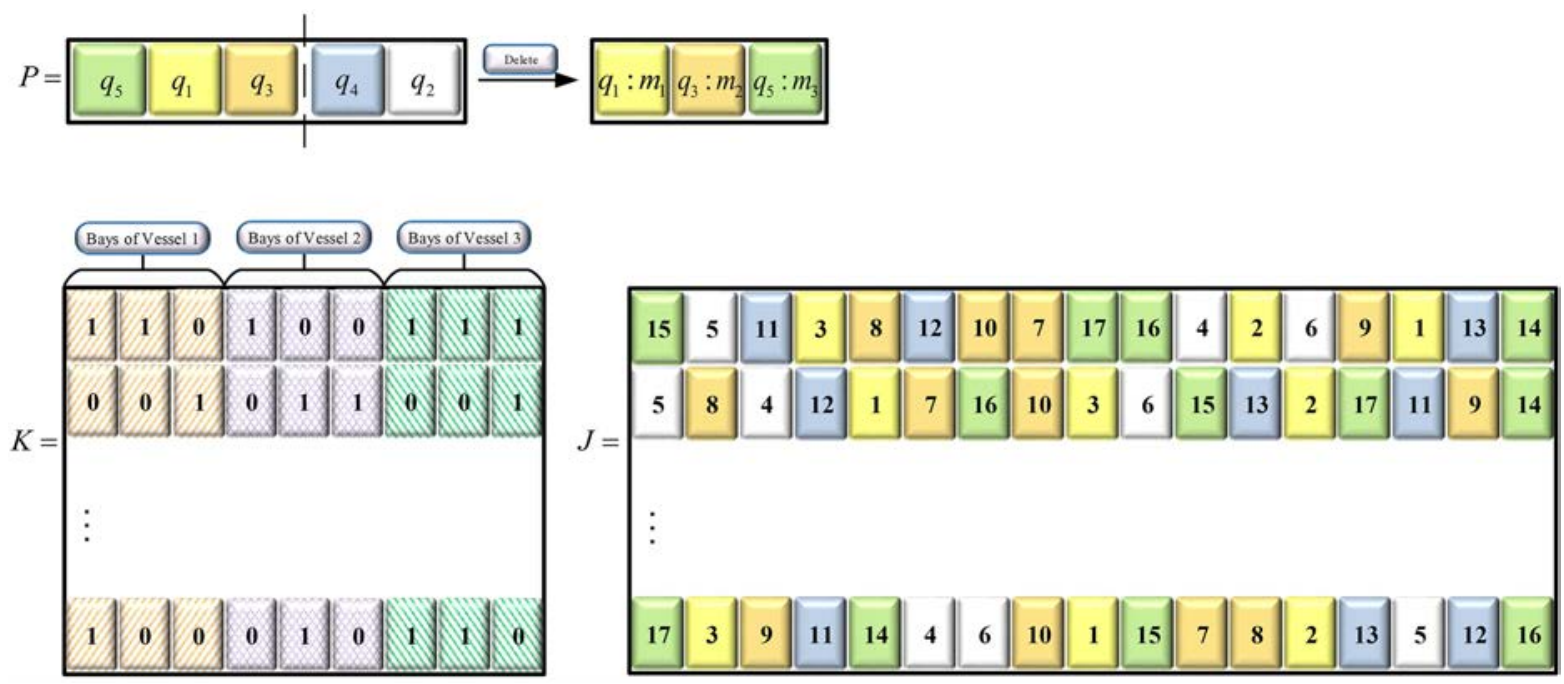

Figure 6. Student structure of numerical example.

constraints of the problem, except Constraint (4). To satisfy Constraint (4), a penalty is used. The computational terms included $y_{i j j^{\prime} q m}^{t}, T_{j m t}, T_{m}^{\prime}, F_{m}$, $E_{m}$ that were separately calculated.

For example, assume five contractors and three vessels. Because of a random solution, a student assigns a contractor to the vessel (Figure 6). In this example, based on the matrix $P$, the first contractor is assigned to the first vessel, the third contractor to the second vessel, and the fifth contractor to the third vessel. If each vessel has three bays, the first row in the matrix $K$ is a random solution representing that during the first period the cranes have been assigned to the first and second bays of the first ship, to the first bay of the second ship, and to the first, second, and third bays of the third vessel. As shown in the above example, the first to fifth contractors have three, three, four, three, and four cranes, respectively. In Figure 6, the matrix $J$ is a random solution to the problem. In this example, cranes 1 to 3 belong to the first contractor, cranes 7 to 10 belong to the third contractor, and Cranes 14 to 17 belong to the fifth contractor. First, the cranes of the selected contractors are assigned to the ships' bays according to matrix $J$ order. Then, the cranes of each ship bay are arranged in ascending order and thus, the possibility of interference in the allocation of the cranes to each vessel is eliminated.

The randomized solution obtained from student decoding for the first time period is shown in Figure 7.

Also, the random solution obtained for assigning contractors and cranes to vessels and bays during the first time period is shown in Figure 8. 


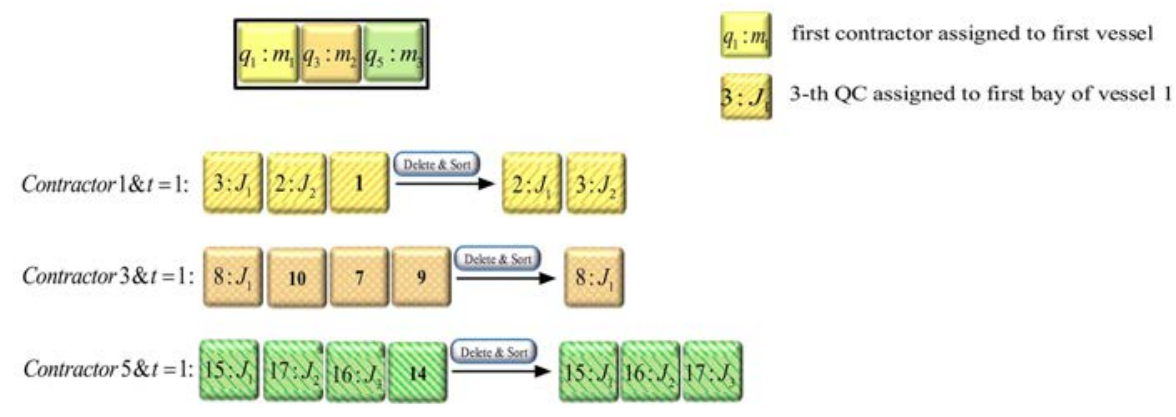

Figure 7. Student decoding of numerical example at $t=1$.

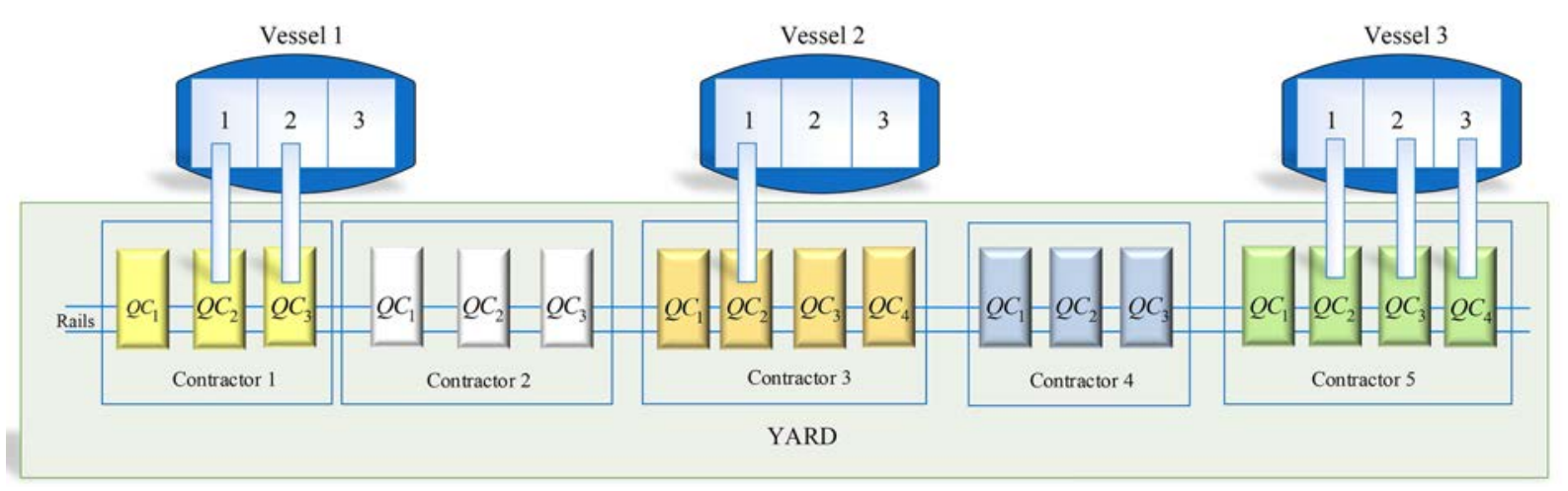

Figure 8. Another presentation of random solution of numerical example at $t=1$.

\section{Result and discussion}

In this section, first, the parameters of the TLBO algorithm are calibrated; then, the performance of the QCASP model presented by the TLBO algorithm is investigated and finally, a case study and sensitivity analysis are presented.

\subsection{Parameter tuning}

One of the important decisions in the metaheuristic algorithms is to caliber the optimal values for the influential parameters $[4,36]$. Although full factorial experiments represent a comprehensive and widely used method for examining the effect of various parameters on the performance of metaheuristic parameters, when the number of factors increases significantly, the process of implementing the method becomes very complicated, which is the reason why it cannot be applied efficiently in this situation [31]. To reduce the number of experiments required, Fractional Factorial Experiments (FFEs) have been developed. FFEs only examine a portion of all possible combinations to estimate the most influential factors and some of their interactions [32].

In case there are fewer data sets in the experimental design, one can save much time and cost to implement it. The data required for an experiment is a function of the number of experiment states and the amount of data needed for each situation. Another criterion that should always be considered in designing experiments is the amount of information collected from the experiments [34-38]. An experimental design should be formed with enough or relatively sufficient amount of information on the field under study. An optimal experiment design provides the data and information needed for performing analysis and achieving optimal conditions with the least number of experiments $[38,39]$. Data analysis method is also effective in choosing an optimal design. An optimal method of data analysis is a method that achieves an optimal combination of factors with the least data. The Taguchi standard orthogonal array designs with a relatively few data sets and relative accuracy have been the most practical ones in estimating both the optimal point and effect of factors, so far. Therefore, in this study, Taguchi method is used to set the parameters and the results are shown in Table 3 [34-38].

Each example of different combinations from the factor level has been solved three times and the obtained mean has been used for the analysis. Figure 9 depicts a plot of the mean $S / N$ ratio at different levels of parameters of the proposed algorithm. Based on this

Table 3. Teaching-Learning-Based-Optimization (TLBO) parameters' level.

\begin{tabular}{ccc}
\hline Level & $\boldsymbol{n}$ Student & $\boldsymbol{T}_{\boldsymbol{F}}$ \\
\hline 1 & 50 & 0.8 \\
2 & 75 & 1.4 \\
3 & 100 & 2.0 \\
\hline
\end{tabular}



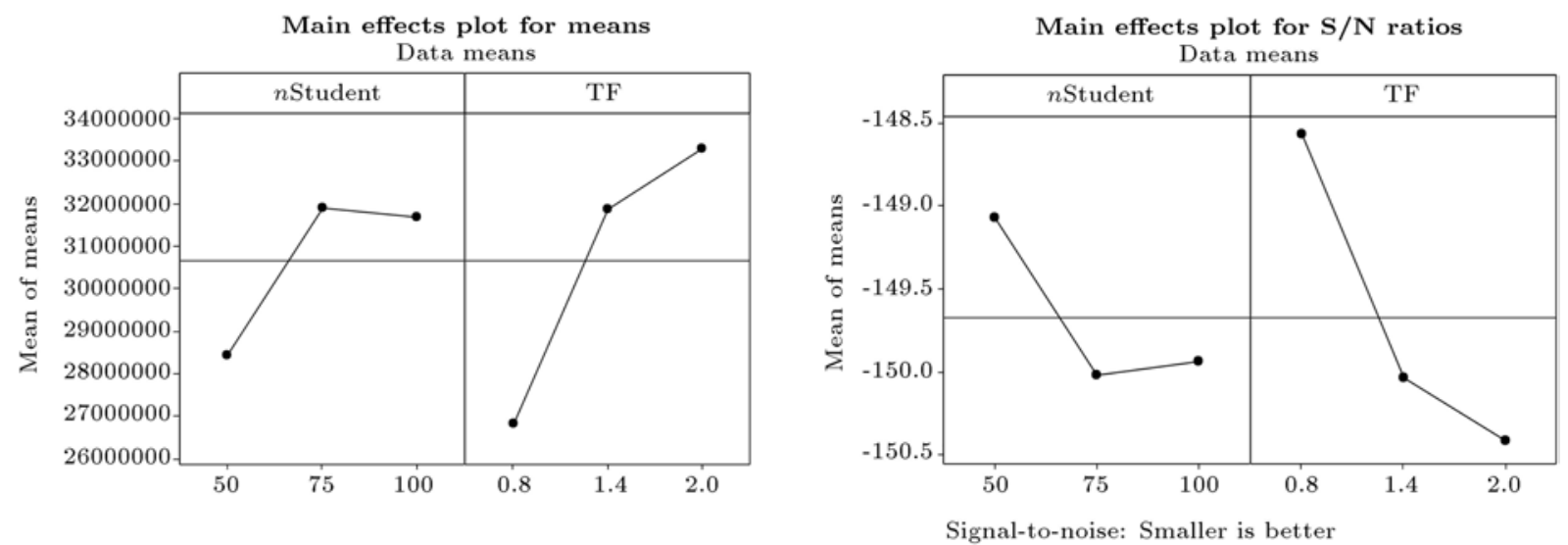

Figure 9. The mean $S / N$ ratio plot for each level of the factors for the proposed algorithms.

figure, the best values for the parameters of the TLBO algorithm are given when $T_{F}=0.8$ and $n$ Student $=100$. These values are used to solve numerical examples using the TLBO algorithm.

\subsection{New numerical example}

In this section, the performance of the QCASP model is presented; then, the TLBO development is verified through 30 small-sized numerical instances and, finally, 10 large-sized instances are presented. Tables S.1., S.2, and S.3 in the Supplementary Materials show the parameters of the instances produced in small and large problems. Because the number of $\lambda_{i j j^{\prime} q m}$ values is quite large and it is not possible to list them in this study, the value of $\lambda_{i j j^{\prime} q m}$ for all vessels, bays, contractors, and cranes is considered 1 to simplify the reference to the mentioned parameter. Small-sized instances are optimally solved by the B\&B method using the LINGO 17.0 software by personal computers with $3.5 \mathrm{GHz}$ and 8 GB RAM. Moreover, all examples are solved by the proposed TLBO algorithm using the MATLAB software. Then, the results obtained from the B\&B method and TLBO algorithm are compared in terms of the Objective Function Value (OFV), CPU time, completion time of vessels $\left(T_{m}^{\prime}\right)$, and tardiness and earliness of vessels $\left(F_{m}, E_{m}\right)$. We also displayed the assignment of contractors to vessels. For example, in the first problem and in both solving methods, the first contractor is assigned to the first vessel; the third contractor to the second vessel; and the fifth contractor to the third vessel, as shown in the assignment column of Appendix D.

Each example is solved 20 times by the TLBO algorithm and, then, the best OFV and other values are reported.

The results of B\&B and TLBO are shown in Table S.4 Supplementary Materials. Based on the results of small-scale instances, one-way analysis of variance (ANOVA) is used to compare the mean responses at a confidence level of $95 \%$ via Minitab software.

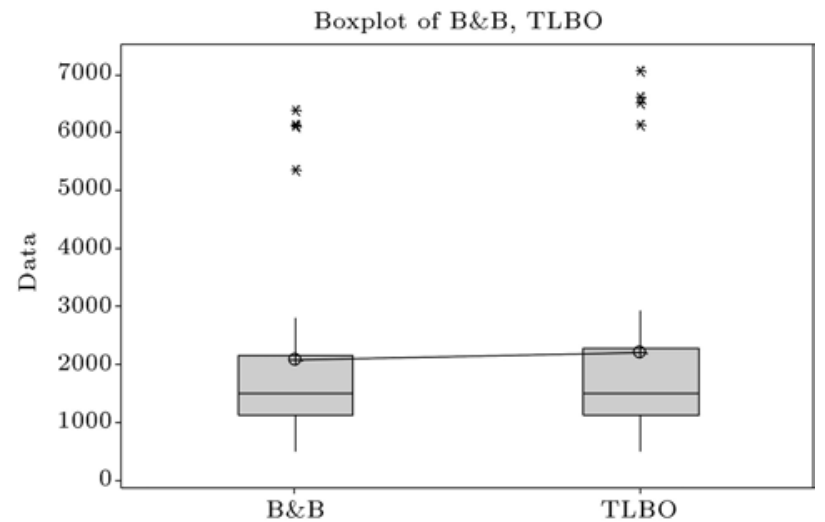

Figure 10. Box-plot of objective function value criterion comparison.

Figure 10 shows the results of ANOVA and since the $\mathrm{P}$-value is greater than 0.05 , there is no significant difference between the results obtained from the TLBO algorithm and the exact solution method. Figure 11 shows that the values of the objective function obtained from the exact method and the proposed algorithm are very close together. As shown in Appendix D, the TLBO function is significantly faster than B\&B algorithm and, thus, in the large-scale problems, $\mathrm{B} \& \mathrm{~B}$ is unable to optimally solve the problem in an acceptable span of time and, therefore, the proposed algorithm can achieve the near-optimal solution much faster.

\subsection{Case study}

In this section, a real case in Shahid Rajaee port of Iran is presented. The following assumption is considered: Vessels 1, 2, 3, and 4 are berthed in this port, which have $4,4,5$, and 3 bays, respectively. They anchored to load 20-feet containers. Because the load type and load density of containers are not the same and the destination of the cargo in each ship bay is different, the containers are not distributed equally in the bays (Table 4 ). On the other hand, there are six Contractors $1,2,3,4,5$, and 6 , which have $4,4,5,4,3$, and 5 cranes, respectively. In container terminals, the cranes 


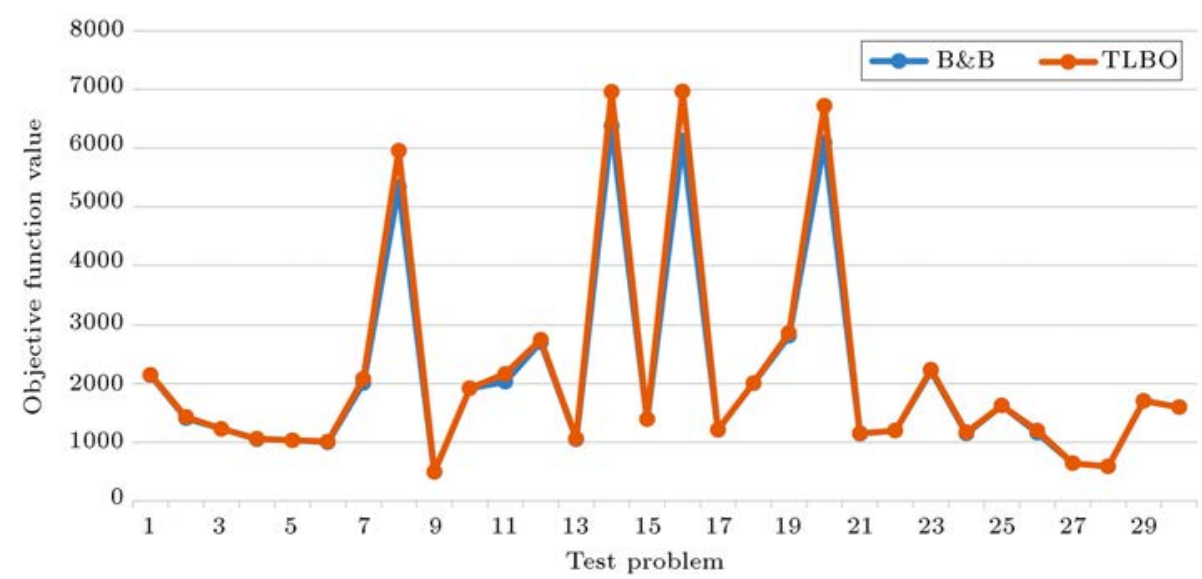

Figure 11. Graphical comparison of solving methodologies in terms of objective function value.

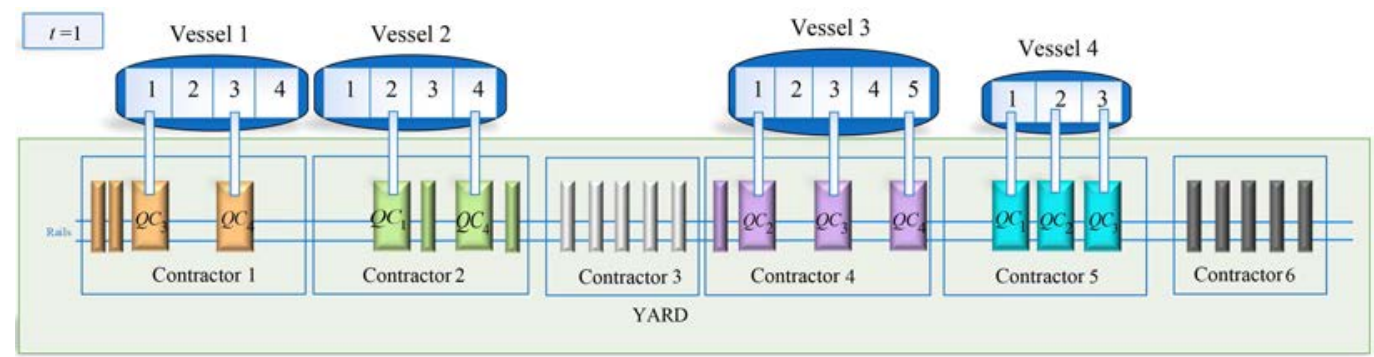

Figure 12. Result obtained for case study at $t=1$.

are busy working day and night and therefore, in this case, each time period is considered to be 24 hours with a maximum number of 20 time period. $\lambda_{i j j^{\prime} q m}$ includes the costs of relocating the cranes between ship bays, opening the hatch of each bay and placing it on the other bay of ship, and reclosing the hatch. Parameters of the problem are shown in Table 4.

As a result of solving the problem, the first contractor is assigned to the first vessel, the second contractor to the second vessel, the fourth contractor to the third vessel, and the fifth contractor to the fourth vessel. Furthermore, the cranes of each contractor are assigned to the ship bays. Cranes that are not working are shown with thinner rectangles. The allocation of the selected cranes to ships in the first time period is schematically shown in Figure 12, and other allocations in the subsequent time periods in the bay-time charts are shown in Figure 13.

Each contractor is displayed with a different color, while the cranes are highlighted with the same color, yet lighter. As shown in Figure 13, loading operations are completed in 13 days for the first vessel, 10 days for the second vessel, 14 days for the third vessel, and 10 days for the fourth vessel. Some cranes are out of order at times to create a balance between the ship bays and prevent the crane interference or congestion.

Table 4. Parameters of case study.

\begin{tabular}{|c|c|c|c|c|}
\hline \multicolumn{5}{|c|}{ Problem information } \\
\hline$\mu_{q}($ container/day $)$ & $D_{m}$ (day) & $\boldsymbol{R}_{m}(\$)$ & $R_{m}^{\prime}(\$)$ & $\lambda_{i j j^{\prime} q m}(\$)$ \\
\hline 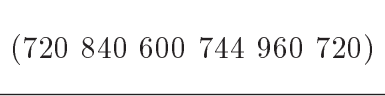 & $\left(\begin{array}{llll}14 & 16 & 13 & 12\end{array}\right)$ & $\begin{array}{l}(240000300000 \\
360000260000)\end{array}$ & $(60000750009000070000)$ & {$[70-150]$} \\
\hline$C(\$)$ & $C^{\prime}(\$)$ & $I_{m}(\$)$ & $C_{q m}^{\prime \prime}(\$)$ & $\omega_{j m}$ (container) \\
\hline 10 & 5000 & $\begin{array}{l}(192000192000 \\
240000144000)\end{array}$ & 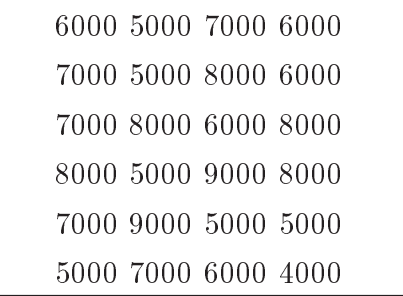 & 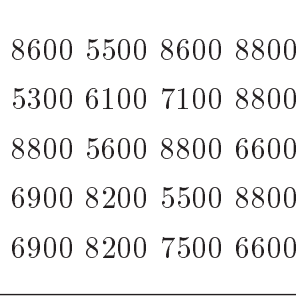 \\
\hline
\end{tabular}



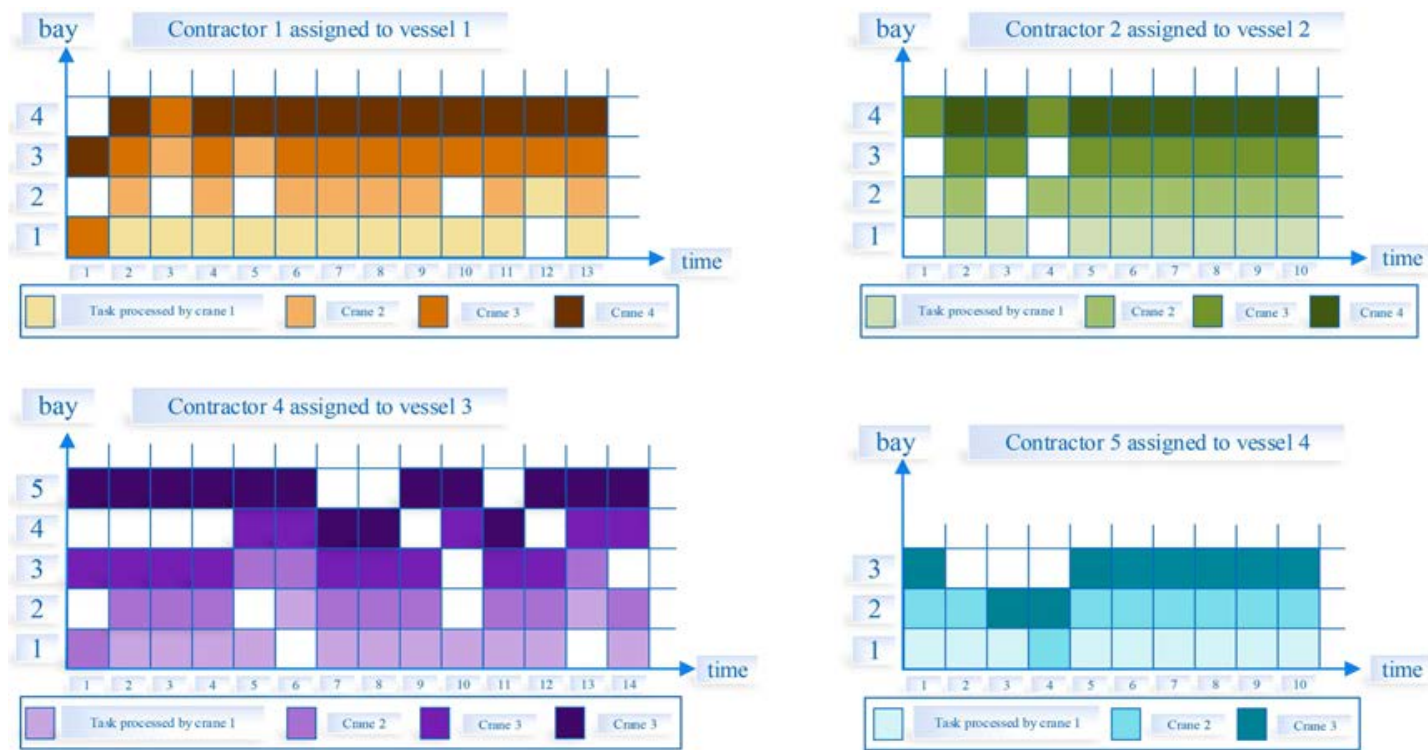

Figure 13. Result obtained for the case study in all time periods.

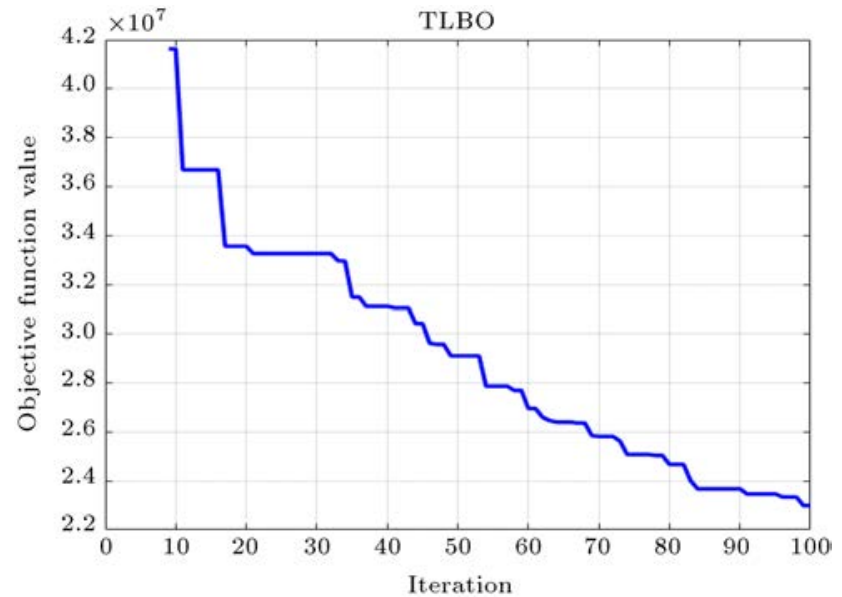

Figure 14. The convergence path of the best result by Teaching-Learning-Based-Optimization (TLBO) algorithm.

The application of this algorithm under the above-mentioned parameters may yield an optimization process whose convergence diagram is depicted in Figure 14. A view of Shahid Rajaee port is shown in Figure 15.

\subsection{Sensitivity analysis}

In this section, sensitivity analysis is carried out to investigate the effect of workload variable in ship bays $\left(\omega_{j m}\right)$ on the OFV as well as the completion time of each vessel. The sensitivity analysis was performed on the case study and the value of $\omega_{j m}$ was at an interval of $\left[0.75 \omega_{j m}-1.25 \omega_{j m}\right]$, which increased 0.05 each time. Table 5 presents the variations of the target function and completion time of ships.

As shipping loads increase at ship bays, relocating and displacing cranes between ship bays, deviations

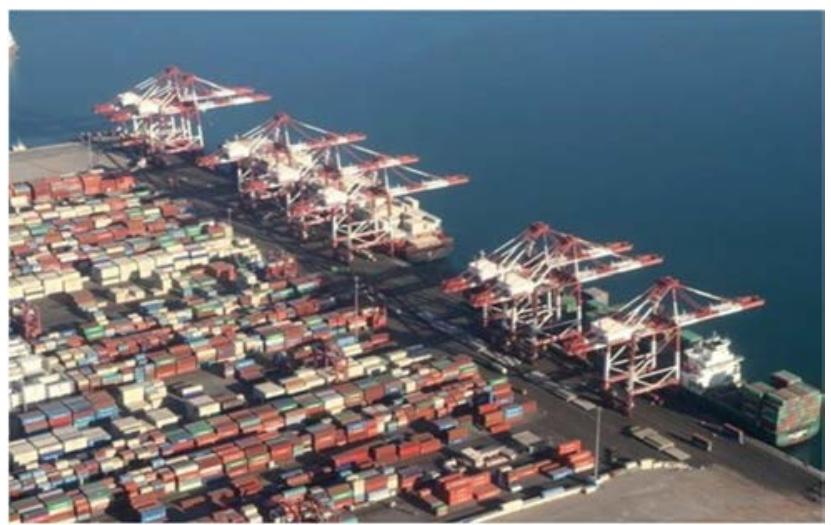

Figure 15. A view of Shahid Rajaee port.

Table 5. The effect of workload at bay $j$ of vessel $m$ to be handled on objective function value and completion time of vessels.

\begin{tabular}{ccccccc}
\hline $\boldsymbol{i}$ & Variable & OFV & $\boldsymbol{T}_{\mathbf{1}}^{\prime}$ & $\boldsymbol{T}_{\mathbf{2}}^{\prime}$ & $\boldsymbol{T}_{\mathbf{3}}^{\prime}$ & $\boldsymbol{T}_{\mathbf{4}}^{\prime}$ \\
\hline 1 & $0.75 \omega_{j m}$ & 13314789 & 10 & 8 & 10 & 7 \\
2 & $0.8 \omega_{j m}$ & 14617002 & 10 & 8 & 11 & 8 \\
3 & $0.85 \omega_{j m}$ & 17677348 & 11 & 9 & 12 & 8 \\
4 & $0.9 \omega_{j m}$ & 18650657 & 11 & 9 & 13 & 9 \\
5 & $0.95 \omega_{j m}$ & 20754603 & 12 & 10 & 13 & 9 \\
6 & $\omega_{j m}$ & 23338524 & 13 & 10 & 14 & 11 \\
7 & $1.05 \omega_{j m}$ & 26897280 & 13 & 13 & 15 & 13 \\
8 & $1.1 \omega_{j m}$ & 27138291 & 14 & 11 & 16 & 11 \\
9 & $1.15 \omega_{j m}$ & 28448528 & 15 & 12 & 16 & 11 \\
10 & $1.2 \omega_{j m}$ & 29936902 & 16 & 14 & 17 & 12 \\
11 & $1.25 \omega_{j m}$ & 31379501 & 16 & 14 & 17 & 12 \\
\hline & & & & & & \\
\hline
\end{tabular}




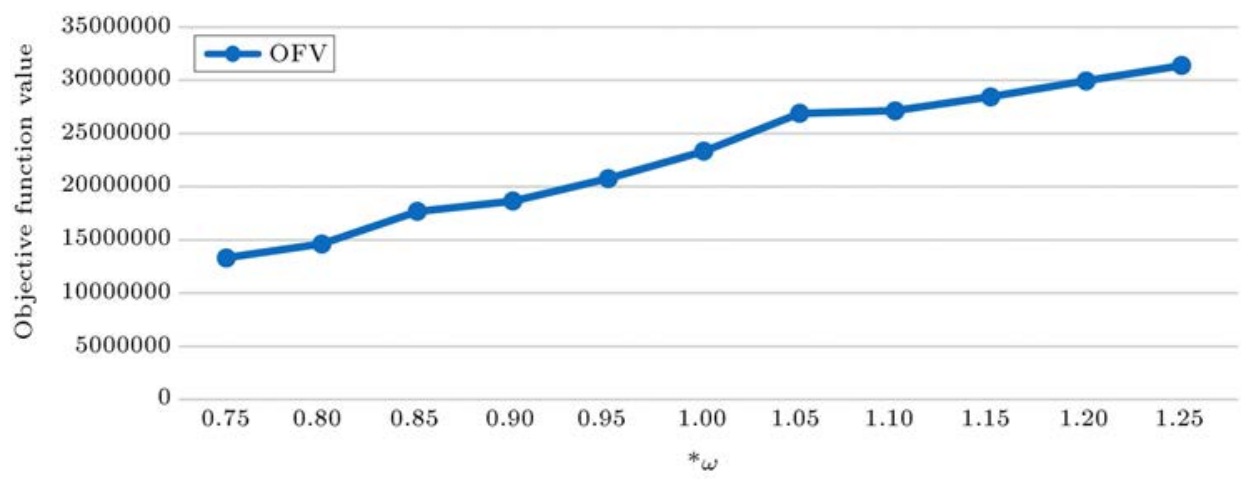

Figure 16. Sensitivity analysis of the effect of workload on Objective Function Value (OFV).

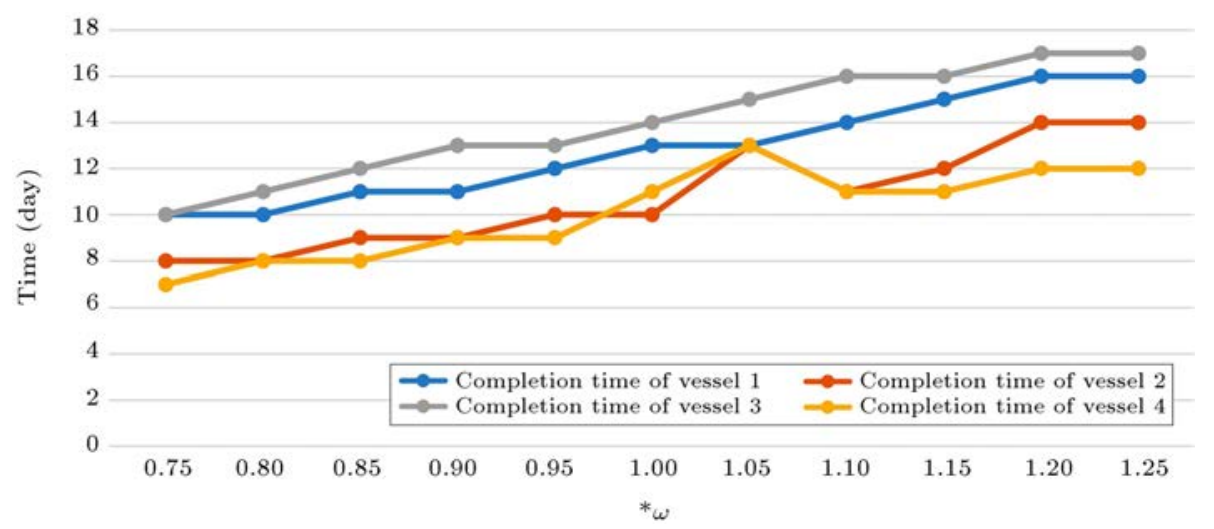

Figure 17. Sensitivity analysis of the effect of workload on completion time of vessels.

from the delivery time, and processing time of cranes per each vessel rise, resulting in the high cost and value of the objective function (Figure 16).

On the other hand, we expect that with an increase in the workload of loading/unloading in the ship bays, the required time for loading and unloading the vessels increases; however, this may not happen in some circumstances. For example, as shown in Figure 17, with an increase in load from $1.05 \omega_{j m}$ to $1.1 \omega_{j m}$, the completion time of the second and fourth vessels decreased. Since the goal is to reduce costs, the reduction of other costs such as the cost of the difference in the remaining load on the ship bays and the cost of the crane's relocation between the bays in some cases can lead to a greater improvement in the value of the objective function. Therefore, although the ship's completion time increased and there might be a delay, the total cost was further reduced. Also, since each crane has at least one period of time on a bay, it may finish its work on the bay earlier and remain idle until the end of that period. In this situation, with a slight increase in the load on that bay, the crane is no longer idle and, eventually, the time of completion of the vessel remains constant. For example, in Figure 17, upon increasing the load from $0.9 \omega_{j m}$ to $0.95 \omega_{j m}$, the completion time of Vessels 3 and 4 remains fixed.

\section{Managerial insights}

In general, the problem of allocating and scheduling cranes is used for terminal management. Optimal use of resources improves the terminal performance and yields greater customer satisfaction. The model presented in this paper follows the following objectives:

- Choosing a good contractor by assigning the position of the contractor's cranes to the vessel such that any interference in the process and in the task of other contractors could be avoided;

- Choosing good contractors in terms of their performance rates, fixed cost of closing a contract with the contractor, and variable cost of using cranes;

- Proper allocation of contractor cranes to the ship bays so that cranes would not disturb each other;

- Considering the priority of servicing ships in terms of due date, tardiness penalty, and benefits of the completion of each ship;

- Considering the cost of moving cranes between the ship's bays to simply avoid displacing the cranes, unless an imbalance between the ships bays has been developed. 


\section{Conclusion}

In this research, Quay Crane Assignment Problem (QCAP) and Quay Crane Scheduling Problem (QCSP) were addressed simultaneously which improved Quay Crane (QC) performance and, consequently, promoted the efficiency of the terminals. Many of the constraints and characteristics of terminals in the real world such as preemption, non-crossing, free movement of cranes to the left and right, etc. were considered in this paper. Since various contractors with different quay cranes have different performance operation rates at the harbor, the contractor's choice was considered based on their situation, performance rate, and costs in this research. The proposed mathematical model solved a problem with real parameters related to Shahid Rajaee port in Iran with Teaching-LearningBased-Optimization (TLBO) algorithm. To investigate the accuracy and verification of the proposed model and the TLBO performance, some small-sized instances were solved. The obtained results showed an acceptable difference between the optimal answer obtained from the Branch\&Bound (B\&B) method and the proposed TLBO algorithm in terms of the objective function value, which is a promising result. Finally, the TLBO algorithm approaches the near-optimal solution in an acceptable span of time. Finally, a set of managerial implications was proposed to improve the drawbacks of the proposed case study using the considered methodology.

This study opens several new research directions for future papers. In the modeling approach, several real constraints can be added to the model. For instance, considering the multi-truck and multi-door case of the proposed problem is a good idea. Of note, no study has investigated the sustainability of the proposed system. Other real cases can be applied to utilize the benefits of the proposed methodology. Regarding the proposed solution algorithm, other powerful and recent metaheuristics and the proposed TLBO can be examined so that the efficiency of the presented results can be compared. Proposing some new variants of TLBO may be a good point of continuation for the current research, as well.

\section{Supplementary Materials}

The Supplementary Materials are available at http://scientiairanica.sharif.edu/jufile?ar_sfile=146526

\section{References}

1. Frojan, P., Correcher, J.F., Alvarez-Valdes, R., Koulouris, G., and Tamarit, J.M., "The continuous Berth allocation problem in a container terminal with multiple quays", Expert Systems with Applications, 42(21), pp. 7356-7366 (2015).
2. Al-Dhaheri, N. and Diabat, A. "The quay crane scheduling problem", Journal of Manufacturing Systems, 36, pp. 87-94 (2015).

3. Diabat, A. and Theodorou, E. "An integrated quay crane assignment and scheduling problem", Computers \& Industrial Engineering, 73, pp. 115-123 (2014).

4. Fathollahi-Fard, A.M., Hajiaghaei-Keshteli, M., and Mirjalili, S. "Multi-objective stochastic closed-loop supply chain network design with social considerations", Applied Soft Computing, 71, pp. 505-525 (2018b).

5. Fathollahi-Fard, A.M. and Hajiaghaei-Keshteli, M. "Integrated capacitated transportation and production scheduling problem in a fuzzy environment", International Journal of Industrial Engineering \& Production Research, 29(2), pp. 197-211 (2018).

6. Hajiaghaei-Keshteli, M. and Fathollahi-Fard, A.M. "A set of efficient heuristics and metaheuristics to solve a two-stage stochastic bi-level decision-making model for the distribution network problem", Computers \& Industrial Engineering, 123, pp. 378-395 (2018).

7. Daganzo, C.F. "The crane scheduling problem", Transportation Research Part B: Methodological, 23(3), pp. 159-175 (1989).

8. Kim, K.H. and Park, Y.M. "A crane scheduling method for port container terminals", European Journal of Operational Research, 156(3), pp. 752-768 (2004).

9. Imai, A., Chen, H.C., Nishimura, E., and Papadimitriou, S. "The simultaneous berth and quay crane allocation problem", Transportation Research Part E: Logistics and Transportation Review, 44(5), pp. 900920 (2008).

10. Goodchild, A.V. and Daganzo, C.F. "Crane double cycling in container ports: Planning methods and evaluation", Transportation Research Part B: Methodological, 41(8), pp. 875-891 (2007).

11. Zhang, H. and Kim, K.H. "Maximizing the number of dual-cycle operations of quay cranes in container terminals", Computers \& Industrial Engineering, 56(3), pp. 979-992 (2009).

12. Tavakkoli-Moghaddam, R., Makui, A., Salahi, S., Bazzazi, M., and Taheri, F. "An efficient algorithm for solving a new mathematical model for a quay crane scheduling problem in container ports", Computers \& Industrial Engineering, 56(1), pp. 241-248 (2009).

13. Bierwirth, C. and Meisel, F. "A survey of berth allocation and quay crane scheduling problems in container terminals", European Journal of Operational Research, 202(3), pp. 615-627 (2010).

14. Zhihong, J.I.N., and Na, L.I. "Optimization of quay crane dynamic scheduling based on berth schedules in container terminal", Journal of Transportation Systems Engineering and Information Technology, 11(3), pp. 58-64 (2011). 
15. Chen, J.H., Lee, D.H., and Cao, J.X. "Heuristics for quay crane scheduling at indented berth", Transportation Research Part E: Logistics and Transportation Review, 47(6), pp. 1005-1020 (2011).

16. Legato, P., Trunfio, R., and Meisel, F. "Modeling and solving rich quay crane scheduling problems", Computers \& Operations Research, 39(9), pp. 20632078 (2012).

17. Al-Dhaheri, N., Jebali, A., and Diabat, A. "The quay crane scheduling problem with nonzero crane repositioning time and vessel stability constraints", Computers \& Industrial Engineering, 94, pp. 230-244 (2016).

18. Liu, C., Zheng, L., and Zhang, C. "Behavior perception-based disruption models for berth allocation and quay crane assignment problems", Computers \& Industrial Engineering, 97, pp. 258-275 (2016).

19. Wu, L. and Ma, W. "Quay crane scheduling with draft and trim constraints", Transportation Research Part E: Logistics and Transportation Review, 97, pp. 38-68 (2017).

20. Agra, A. and Oliveira, M. "MIP approaches for the integrated berth allocation and quay crane assignment and scheduling problem", European Journal of Operational Research, 264(1), pp. 138-148 (2018).

21. Azevedo, A.T., de Salles Neto, L.L., Chaves, A.A., and Moretti, A.C. "Solving the 3D stowage planning problem integrated with the quay crane scheduling problem by representation by rules and genetic algorithm", Applied Soft Computing, 65, pp. 495-516 (2018).

22. Liang, C., Fan, L., Xu, D., Ding, Y., and Gen, M. "Research on coupling scheduling of quay crane dispatch and configuration in the container terminal", Computers \& Industrial Engineering, 125, pp. 649-657 (2018).

23. Zhang, A., Zhang, W., Chen, Y., Chen, G., and Chen, X. "Approximate the scheduling of quay cranes with non-crossing constraints", European Journal of Operational Research, 258(3), pp. 820-828 (2017).

24. Kaveshgar, N., Huynh, N., and Rahimian, S.K. "An efficient genetic algorithm for solving the quay crane scheduling problem", Expert Systems with Applications, 39(18), pp. 13108-13117 (2012).

25. Chen, J.H. and Bierlaire, M. "The study of the unidirectional quay crane scheduling problem: complexity and risk-aversion", European Journal of Operational Research, 260(2), pp. 613-624 (2017).

26. Lee, D.H., Wang, H.Q., and Miao, L. "Quay crane scheduling with non-interference constraints in port container terminals", Transportation Research Part E: Logistics and Transportation Review, 44(1), pp. 124135 (2008).
27. Fard, A.M.F. and Hajiaghaei-Keshteli, M. "Red Deer Algorithm (RDA); a new optimization algorithm inspired by Red Deers' mating", In International Conference on Industrial Engineering, IEEE, 12, pp. 331342 (2016).

28. Bhattacharjee, K., Bhattacharya, A., and Dey, S.H.N. "Teaching-learning-based optimization for different economic dispatch problems", Scientia Iranica, Transaction D, Computer Science \& Engineering, Electrical, 21(3), p. 870 (2014).

29. Fathollahi-Fard, A.M., Hajiaghaei-Keshteli, M., and Tavakkoli-Moghaddam, R. "A bi-objective green home health care routing problem", Journal of Cleaner Production, 200, pp. 423-443 (2018a).

30. Rao, R.V., Savsani, V.J., and Vakharia, D.P. "Teaching-learning-based optimization: A novel method for constrained mechanical design optimization problems", Computer-Aided Design, 43(3), pp. 303-315 (2011).

31. Fu, Y., Tian, G., Fathollahi-Fard, A.M., Ahmadi, A., and Zhang, C. "Stochastic multi-objective modelling and optimization of an energy-conscious distributed permutation flow shop scheduling problem with the total tardiness constraint", Journal of Cleaner Production, 226, pp. 515-525 (2019).

32. Asim, M., Zubair Khan, M., Alam Khan, L., and Umer, M. "An integrated approach of quality for polymer composite manufacturing validated and optimized through Taguchi method", Scientia Iranica, 24(4), pp. 1985-1995 (2017).

33. Jamshidi, R., Ghomi, S.F., and Karimi, B. "Multiobjective green supply chain optimization with a new hybrid memetic algorithm using the Taguchi method", Scientia Iranica, 19(6), pp. 1876-1886 (2012).

34. Fathollahi-Fard, A.M., Hajiaghaei-Keshteli, M., and Tavakkoli-Moghaddam, R. "A Lagrangian relaxationbased algorithm to solve a home health care routing problem", International Journal of Engineering, 31(10), pp. 1734-1740 (2018).

35. Fathollahi-Fard, A.M., Hajiaghaei-Keshteli, M., and Mirjalili, S. "Hybrid optimizers to solve a tri-level programming model for a tire closed-loop supply chain network design problem", Applied Soft Computing, 70, pp. 701-722 (2018c).

36. Mohammadzadeh, H., Sahebjamnia, N., FathollahiFard, A.M., and Hahiaghaei-Keshteli, M. "New approaches in metaheuristics to solve the truck scheduling problem in a cross-docking center", International Journal of Engineering-Transactions B: Applications, 31(8), pp. 1258-1266 (2018).

37. Fathollahi-Fard, A.M. "A set of efficient heuristics for a home healthcare problem", Neural Computing and Applications, 32(10), pp. 6185-6205 (2020).

38. Imai, A., Yamakawa, Y., and Huang, K. "The strategic berth template problem", Transportation Research Part E: Logistics and Transportation Review, 72, pp. 77-100 (2014). 
39. Safaeian, M., Fathollahi-Fard, A.M., Tian, G., Li, Z., and Ke, H. "A multi-objective supplier selection and order allocation through incremental discount in a fuzzy environment", Journal of Intelligent \& Fuzzy Systems, 37(1), pp. 1435-1455 (2019).

\section{Biographies}

Mojgan Safaeian was born in Behbahan, Iran and raised in Tehran, Iran. She earned her BSc degree in Computer Science from Sheikh-Bahaee University, Isfahan, Iran (2010). She also received her MSc degree in Industrial Engineering from Azad University, Qazvin, Iran (2013).

Farhad Etebari received his BS degree in Industrial Engineering from Sharif University of Technology and his MS and PhD degrees in Industrial Engineering from
K.N. Toosi University of Technology. He is currently an Assistant Professor in Industrial Engineering at Azad University of Qazvin, Qazvin, Iran. His research interests include optimization models, logistic systems, transportation networks design, transportation planning, and AI algorithms.

Behnam Vahdani was born and raised in Tehran, Iran. He earned his BSc from Azad University, Tehran, Iran (2006); MSc from Azad University, Qazvin, Iran (2009); and PhD from Tehran University, Tehran, Iran (2014), all in Industrial Engineering. $\mathrm{He}$ is currently an Assistant Professor in Industrial Engineering at Azad University of Qazvin, Qazvin, Iran. The main focus of his research is in the area of supply chain network, transportation, metaheuristics, healthcare management, and green and sustainable logistics. 